\title{
Erratum to: Identification of the NEDD4L Gene as a Prognostic Marker by Integrated Microarray Analysis of Copy Number and Gene Expression Profiling in Non-small Cell Lung Cancer
}

Hiroyuki Sakashita, $\mathrm{MD}^{1,2,5,6}$, Hiroshi Inoue, MD, $\mathrm{PhD}^{1}$, Shinji Akamine, MD, $\mathrm{PhD}^{3}$, Teruyoshi Ishida, $\mathrm{MD} \mathrm{PhD}^{4}$, Naohiko Inase, MD, $\mathrm{PhD}^{5}$, Kuniaki Shirao, MD, $\mathrm{PhD}^{6}$, Masaki Mori, MD, PhD, FACS ${ }^{1,7}$, and Koshi Mimori, MD, PhD $^{1,8}$

${ }^{1}$ Department of Molecular and Surgical Oncology, Medical Institute of Bioregulation, Kyushu University, Beppu, Japan; ${ }^{2}$ Department of Clinical Oncology, Tokyo Medical and Dental University, Tokyo, Japan; ${ }^{3}$ Department of Chest Surgery, Oita Prefectural Hospital, Oita, Japan; ${ }^{4}$ Department of Surgery, Hiroshima Red Cross Hospital \& Atomic-bomb Survivors Hospital, Hiroshima, Japan; ${ }^{5}$ Department of Integrated Pulmonology, Graduate School of Medicine, Tokyo Medical and Dental University, Tokyo, Japan; ${ }^{6}$ Department of Medical Oncology, Oita University, Oita, Japan; ${ }^{7}$ Department of Gastroenterological Surgery, Graduate School of Medicine, Osaka University, Suita, Japan; ${ }^{8}$ Department of Surgery, Kyushu University Beppu Hospital, Beppu, Japan

ERRATUM TO: ANN SURG ONCOL (2013) 20:S590-S598

\section{DOI 10.1245/S10434-013-3059-6}

Figure $2 \mathrm{~b}$ was incorrect in the original article. The correct figure is as follows:

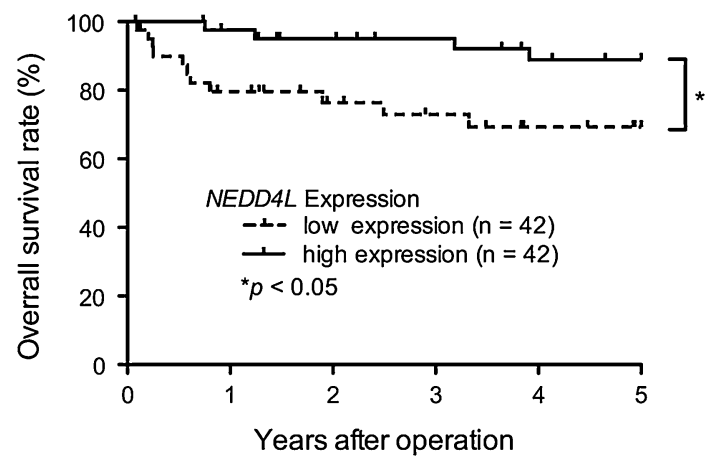

FIG. 2 b Kaplan-Meier survival curves of lung cancer patients according to $N E D D 4 L$ mRNA expression. Patients with low NEDD4L expression in tumors showed significantly shorter survival ( $\mathrm{p}=0.0187 ; \log$-rank test) than those with high $N E D D 4 L$ expression in tumors

The online version of the original article can be found under doi:10.1245/s10434-013-3059-6.

(C) Society of Surgical Oncology 2014

Published Online: 14 January 2014

H. Sakashita, MD

e-mail: hsakashita.pulm@tmd.ac.jp 